\title{
RESTRIC̣̃̃ES COGNITIVAS NO LIVRO DIDÁTICO DE BIOLOGIA: UM ESTUDO A PARTIR DO TEMA “CICLO DO NITROGÊNIO"
}

\begin{abstract}
Francisco Ângelo Coutinho*
Adriana Gonçalves Soares**

RESUMO: Fundamentando-se em um modelo de aprendizagem a partir de recursos que fazem uso de texto verbal e imagem, e na teoria da carga cognitiva, o artigo analisa quatro coleções de livros didáticos de Biologia. Para nossa análise, elegemos como tema o "Ciclo do Nitrogênio". A análise evidenciou um planejamento instrucional inadequado, que sobrecarrega os recursos cognitivos do aluno. Assim, o estudo das quatro coleções indica a necessidade de que o planejamento e a construção de imagens para o livro didático de Biologia sejam orientados por preceitos e critérios que visem tornar o uso dos recursos pictóricos mais eficientes. Ao final, propomos algumas indicações para a área de pesquisa e ensino em
\end{abstract} Ciências e Biologia.

Palavras-chave: Ensino de Biologia; Livro Didático; Memória Operacional; Carga Cognitiva.

COGNITIVE RESTRICTIONS IN THE BIOLOGY TEXTBOOK: A STUDY ON THE THEME "THE NITROGEN CYCLE"

ABSTRACT: Based on a learning study on resources that use verbal text and image and the theory of cognitive load, the article analyzes four collections of Biology textbooks. For our analysis, we chose the theme "The Nitrogen Cycle", which showed inadequate instructional planning, overloading the cognitive resources of the student. Thus, the study of the four collections indicates the need for a better planning of images in the Biology textbook guided by criteria aiming to make the use of pictorial resources more effective. At the end we propose a few indications for the area of research and the teaching of Science and Biology.

Keywords: Biology Teaching; Textbooks; Working Memory; Cognitive Load. 


\section{Introdução}

O uso de imagens aliadas a texto verbal é de significativa importância nas Ciências Naturais. Os cientistas utilizam constantemente imagens em seus laboratórios, apresentações e artigos (POZZER-ARDENGHI; ROTH, 2005). Tais imagens incluem mapas, fotografias, diagramas, tabelas, fórmulas, simulações, etc. Segundo Pozzer-Ardenghi e Roth (2005), as imagens são singularmente importantes para a construção do conhecimento científico. Elas constituem um meio amplamente aceito no diálogo científico, tendo um potencial particular para comunicar aspectos da natureza e para indicar o conteúdo de ideias. KnorrCetina e Amann (1990), por exemplo, afirmam que, embora os filósofos, historiadores e sociólogos da ciência tenham considerado a escrita como a parte central da atividade científica, na verdade, o foco de muitas atividades de laboratório não é o texto, mas as imagens. Como diz Bruzzo (2004): "Conhecer a natureza também é expressar esse conhecimento em palavras e imagens criadas para este fim".

Deste modo, a ciência não é feita ou comunicada somente por meio da linguagem verbal. Os conceitos científicos, embora tenham um importante componente verbal, são, em uma expressão de Lemke, híbridos semióticos (LEMKE, 1998). Quando os cientistas pensam, falam, escrevem e ensinam, eles combinam, interconectam e integram o texto verbal com expressões matemáticas, tabelas, gráficos, fotografias, diagramas, mapas, desenhos, esquemas, simulações, ou seja, todo um conjunto de gêneros visuais especializados (LEMKE, 1998). As imagens, portanto, estabelecem-se como importantes instrumentos de comunicação de ideias científicas (MARTINS et al., 2005).

O uso de imagens, por conseguinte, não poderia deixar de se difundir também nos livros didáticos de Biologia do ensino médio. Nestes livros, as imagens têm presença destacada. Muitas vezes, as razões oferecidas para esta presença vão desde as alegações sobre o interesse da indústria editorial, ao desinteresse dos alunos pela leitura (BRUZZO, 2004). Aqui, no entanto, compartilhamos da perspectiva de que a comunicação científica tem caráter multimodal, envolvendo a articulação de linguagem verbal e linguagem imagética (PICCININI; MARTINS, 2004). A nosso ver, as representações visuais nos livros didáticos contam entre os modos semióticos de construção de sentidos. As imagens não seriam, então, meras ilustrações com função acessória (BRUZZO, 2004). Elas possuem valor cognitivo e cumprem importantes funções mediadoras na apropriação da linguagem da ciência escolar pelo aluno, e mesmo para o professor.

Esta posição alinha-se a resultados de pesquisas na área de psicologia cognitiva. Diversas pesquisas realizadas por Mayer e colaboradores (p. ex., MAYER; GALLINI, 1990; MAYER; ANDERSON, 1991 e 1992 e MAYER, 2001) demonstram que se aprende melhor por meio de palavras e imagens que por meio de palavras somente. No entanto, como veremos, nem toda relação texto-imagem é igual- 
mente eficiente em promover a aprendizagem. Simplesmente adicionar palavras e imagens não garante acesso à aprendizagem (MAYER, 2005).

Torna-se, assim, importante compreender como se dá o uso de imagens nos livros didáticos de Biologia e indicar qual a melhor forma de se incorporar imagens e texto verbal nestes livros. Ainda, uma vez compreendidos os obstáculos a uma aprendizagem eficiente promovidos pela diagramação e planejamento inadequados do livro didático, o professor pode desenvolver e utilizar estratégias que minimizem os problemas encontrados.

O ponto de partida de nossa pesquisa é a ideia de que as mensagens instrucionais planejadas a partir dos resultados de pesquisas de como o sistema cognitivo humano funciona têm maior possibilidade de promover uma aprendizagem eficiente (MAYER, 2005). Buscamos, então, num primeiro momento, explicitar algumas ideias sobre a arquitetura cognitiva humana, advindas da psicologia cognitiva e da neurociência cognitiva. Na sequência, a partir de alguns aspectos da cognição humana, extraímos algumas conclusões sobre a melhor maneira de se construir relações entre texto e imagem. Justo a isto, apresentamos a análise de alguns livros didáticos de Biologia. Nas considerações finais, projetamos algumas indicações para a área de pesquisa em ensino de Biologia, bem como fornecemos indicações para o trabalho do professor em sala de aula.

Antes de prosseguirmos, convém alertar que este estudo não tem por objetivo avaliar ou buscar erros conceituais nos livros didáticos aqui analisados. Trata-se de apresentar alguns problemas com o planejamento e o layout destes livros. Estes problemas dizem respeito, fundamentalmente, à imposição de restrições cognitivas à aprendizagem, ou seja, obstáculos à aprendizagem advindos de uma sobrecarga no sistema cognitivo do aluno. Ao mesmo tempo, almeja-se apresentar um referencial teórico-metodológico que disponibiliza ferramentas que, acreditamos, em muito podem contribuir para se criar estratégias para o planejamento do livro didático de Biologia, bem como para seu uso em sala de aula.

Ainda, toda pesquisa deve fazer um recorte de seu objeto e, somente depois, avançar estudando outros casos afins e procurando generalizações. Esta indicação metodológica baseia-se no fato de que qualquer fenômeno é por demasiado complexo para ser esgotado no âmbito de um artigo. Consequentemente, fizemos este recorte escolhendo como tema de análise o Ciclo do Nitrogênio. Esta escolha encontra, pelo menos, três justificativas: a) a importância do Ciclo do Nitrogênio para o equilíbrio energético do ambiente e para a formação de compostos nitrogenados essenciais para os seres vivos (CAMPOS; LIMA, 2008); b) o fato de o tema ser recursivamente tratado e exposto a partir de texto e imagem nos livros didáticos; e c) nossa prática de sala de aula mostra que, entre os Ciclos Biogeoquímicos, o Ciclo do Nitrogênio é o que os alunos apresentam maior dificuldade em compreender. Esta última indicação, por si, aponta para o fato de que o tema demanda investigação. 


\section{Alguns elementos da arquitetura cognitiva humana e o conceito de carga cognitiva}

Nosso estudo baseia-se em três princípios teóricos sobre a aprendizagem (MAYER, 2005): a) o sistema humano de processamento de informação inclui dois canais, um canal visual/pictórico e outro um verbal/auditivo; b) devido aos limites do sistema de memória, cada canal tem uma capacidade limitada de processamento de informação; c) os seres humanos se engajam ativamente no processo de cognição durante a aprendizagem.

A concepção de canais separados para o processamento da informação está associada à teoria do código duplo (PAIVIO, 1986; CLARK; PAIVIO, 1991). De acordo com esta teoria, a cognição humana utiliza um sistema de códigos para representar a informação verbal e outro para representar a informação visual. As imagens mentais são códigos analógicos e nossas representações mentais de palavras são realizadas em um código simbólico. Estes dois códigos organizam a informação em conhecimentos para a ação, armazenamento e recuperação posterior (STERNBERG, 2008, p. 226-228). Assim, a percepção tanto de textos quanto de imagens se dá por meio dos olhos; porém, após a entrada pelo sistema perceptivo, textos são transferidos para o canal verbal e imagens para o canal pictórico.

Porém, os seres humanos têm uma capacidade limitada quanto ao total de informação que podem processar (MAYER, 2005). Esta limitação é, em grande parte, devida ao funcionamento do sistema mnemônico humano. Quando um evento qualquer ativa o sistema neural, como ler uma palavra, analisar uma figura ou ouvir um som não verbal, o primeiro processo ocorre na chamada memória sensorial (LENT, 2001, p. 599-600). Esta memória tem a característica de ser pré-consciente e ter um limite de retenção ultra-rápido (LENT, 2001, p. 600).

Após a entrada da informação e sua passagem pela memória sensorial, o próximo passo é a seleção do que poderá ser armazenado durante um tempo suficiente para orientar o raciocínio imediato, a resolução de problemas ou para a ação comportamental (LENT, 2001, p. 600). Este tipo de memória é denominado memória operacional. A memória operacional é definida como um sistema ativo de memória que é responsável, simultaneamente, pela manutenção e processamento da informação (BAYKISS et al., 2005). A memória operacional é um sistema de capacidade limitada que armazena e manipula a informação temporariamente para a execução de tarefas complexas, tais como compreensão, aprendizagem e raciocínio (BASSELEY, 2000). Deve-se ressaltar que a memória operacional não lida exclusivamente com informações provenientes da memória sensorial, utiliza também informações armazenadas na memória de longa duração (LENT, 2001, p. 600).

Segundo o modelo de Baddeley (1992 e 2000), construído a partir de evidências de experimentos fisiológicos, neurologia clínica e psicologia cognitiva, a memória operacional é constituída por um componente conhecido como executivo central e três componentes de apoio: a alça fonológica, o esboço visoespacial e o buffer episódico. O componente executivo extrai informação da 
memória de longa duração e coordena a atividade dos demais componentes. É ele que decide qual informação processar mais e como fazê-lo. Um dos papéis do componente executivo é decidir como dividir a atenção entre diferentes tarefas (GOLDSTEIN, 2008, p. 156). A alça fonológica mantém por pouco tempo a informação para a compreensão verbal e para a repetição acústica. $\mathrm{O}$ esboço viso-espacial guarda por um tempo curto algumas imagens visuais. Finalmente, o buffer episódico é um sistema de capacidade limitada que conecta a informação dos sistemas subsidiários e da memória de longo prazo em uma representação episódica unitária (STERNBERG, 2008, p. 168-169).

Além de ser um tipo de memória de curta duração, que perde seu conteúdo em torno de 20 segundos (PETERSON; PETERSON, 1959), a memória operacional é severamente limitada também quanto à quantidade de informação que pode reter. Miller (1956) demonstrou que a memória operacional é capaz de manter somente sete elementos de informação e pode processar, no sentido de combinar, contrastar ou manipular, não mais do que 2 a 4 elementos de informação.

Assim, quando um aluno se depara com uma ilustração, somente partes dos detalhes podem ser retidas na memória operacional, devido à capacidade limitada desta de reter e manipular informações. O aluno, então, constrói uma imagem mental a partir de alguns detalhes da imagem, e não uma cópia exata do material apresentado. $O$ fato de não sermos capazes de fazer uma cópia exata do material apresentado, mas tão somente lidar com fragmentos da informação, vale para ler um texto, assistir a um documentário ou analisar uma simulação composta de imagens (paradas e em movimento), textos e sons (MAYER, 2005).

O próximo passo é a retenção da informação na memória de longo prazo. Neste processo, alguns aspectos selecionados ficam disponíveis para serem lembrados. Diferentemente da memória operacional, a memória de longo prazo tem uma capacidade muito grande e pode armazenar informações por longos períodos de tempo (STERNBERG, 2008, p. 160; MAYER, 2005). Deste modo, os seres humanos se engajam ativamente no processo de cognição, com o objetivo de construir uma representação mental coerente da experiência. Este processo ativo envolve atenção, organização da informação e integração desta com outros conhecimentos (MAYER, 2005).

Segundo Mayer (2005), para que uma aprendizagem eficiente ocorra, quando se trata de uma aprendizagem a partir de texto e imagem, o aluno emprega cinco processos cognitivos: 1) selecionar palavras relevantes para o processamento na memória operacional verbal; 2) selecionar imagens relevantes para o processamento na memória operacional visual; 3) organizar as palavras selecionadas em um modelo verbal; 4) organizar as imagens selecionadas em um modelo visual; e, finalmente, 5) integrar as representações verbais e visuais com um conhecimento prévio. A Figura 1 sumariza estes eventos. Deve-se marcar que estes processos não ocorrem necessariamente nesta ordem linear. O que importa é notar que a aprendizagem requer que o aluno coordene e monitore estes cinco processos (MAYER, 2005). 
Figura 1: Teoria cognitiva da aprendizagem a partir de texto e imagem.

Modificado a partir de Mayer (2005, p. 37)

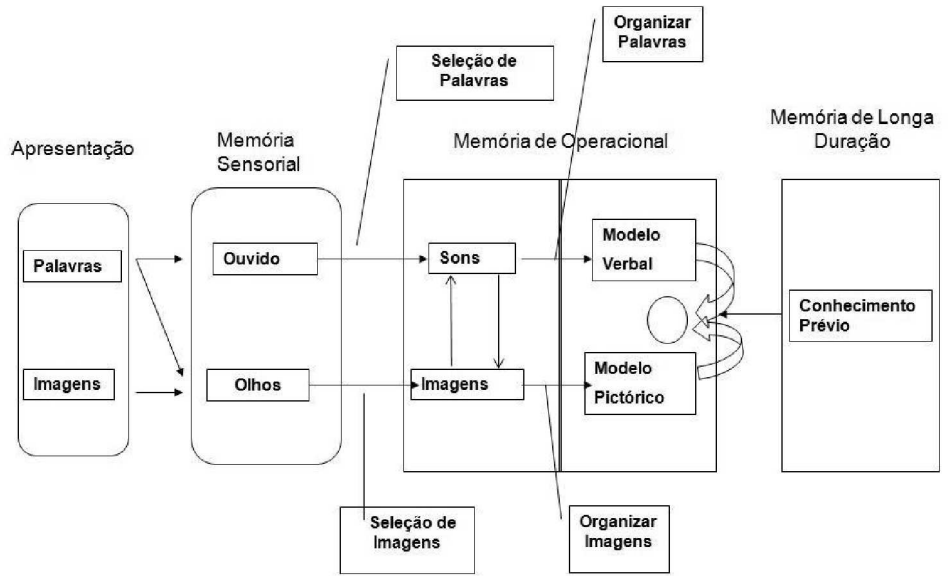

Segundo este modelo, portanto, o material instrucional que faz uso de imagens e texto escrito será tanto mais efetivo quanto mais seu planejamento estiver alinhado à arquitetura cognitiva humana. Este pressuposto assenta-se sobre a ideia de que uma carga cognitiva supérflua ocorrerá quando o material instrucional desconsiderar alguns princípios básicos de construção (SWELLER, 1988 e 2005). A carga cognitiva é o resultado das demandas sobre a memória operacional e resulta do esforço imposto pela informação que deve ser mantida na memória operacional mais a informação que deve ser processada. Por exemplo, somar 3 e 5 é relativamente fácil, pois impõe pouca carga sobre a memória operacional. No entanto, multiplicar 725 por 93, de cabeça, impõe um grande esforço, pois deve-se reter simultaneamente os produtos intermediários do cálculo na memória operacional enquanto se realiza os demais passos da operação (CLARK; LYONS, 2004, p. 106). Existem três categorias de carga cognitiva: supérflua, intrínseca e efetiva.

A carga cognitiva supérflua é causada por planejamento instrucional inapropriado, que ignora ou não respeita os limites da memória operacional (SWELLER, 2005). Por exemplo, quando um texto verbal possui passagens interessantes, mas desnecessárias para a compreensão do tópico de ensino ou quando a imagem possui elementos estranhos ou desnecessários. Neste caso, exigese do aluno um processamento supérfluo, que é definido como aquele requerido quando uma mensagem instrucional contém muitos detalhes, adornos, informação gratuita, ou quando o layout do material é confuso (MAYER, 2005, p. 198).

A carga cognitiva intrínseca é devida à complexidade natural da informação que deve ser processada. Ela é determinada pelo nível de interatividade 
dos elementos. Por exemplo, na aprendizagem de uma fórmula de reação, a simplificação ou exclusão de qualquer informação inerente à reação pode prejudicar a compreensão do processo. Assim, o conteúdo da informação não pode ser alterado sem prejuízos da aprendizagem.

Finalmente, a carga cognitiva efetiva é aquela resultante do esforço em se adquirir conhecimentos. Por exemplo, fornecer ao aluno uma série de exercícios pode aumentar a carga cognitiva efetiva, mas é provável que facilite a memorização ou a aprendizagem significativa.

Portanto, um dos maiores desafios dos planejadores e produtores de materiais didáticos é criar mensagens instrucionais que são sensíveis ou alinhadas às características do sistema cognitivo humano, de tal modo que o total do processamento requerido não exceda os limites em cada canal da memória operacional do aluno (MAYER, 2005). Alcançar um processamento cognitivo toma tempo e requer esforço por parte do aluno e estes recursos são limitados. Se for requerido do aluno que ele se dedique a um processamento de informação desnecessária, ele pode não ser capaz de dar sentido ao material essencial e, portanto, a aprendizagem estará comprometida.

\section{Análise do tema Ciclo do Nitrogênio em livros didáticos de Biologia do Ensino Médio}

Como pôde ser visto, todo material didático apresenta alguma carga cognitiva. Algumas são inerentes ao próprio material instrucional e outras são devidas à necessidade de fixação do conteúdo. Existe, no entanto, aquela categoria que é devida ao planejamento inadequado ou ao layout confuso do material. Esta carga cognitiva supérflua poderia ser eliminada se fossem atendidos certos princípios de planejamento. Nos últimos vinte anos, pesquisas empíricas guiadas por teorias e modelos de cognição expostos acima, visaram encontrar princípios e estratégias que eliminassem ou minimizassem os efeitos da carga cognitiva supérflua de materiais instrucionais e, consequentemente, sobre o sistema cognitivo do aluno.

Em nosso estudo, aproveitamo-nos de alguns dos achados destas pesquisas para análise do tema Ciclo do Nitrogênio em quatro livros didáticos de Biologia para o ensino médio. Porém, como se verá, nossa análise apontou outros problemas no planejamento de livros didáticos que ainda não foram explorados na literatura, embora possam ser correlacionados com o modelo cognitivo que utilizamos como referencial teórico. Assim, propomos três novos princípios que deveriam ser considerados quando se planeja um material instrucional que faz uso de texto verbal e imagens. Os livros analisados por nós foram Amabis e Martho (2004, volume 3), Linhares e Gewandsznajder (2003, volume 3), Paulino (2002, volume 3) e César e Sezar (2005, volume 3). A escolha destes livros foi feita por enquete junto a 25 professores do ensino médio.

Nossa análise, inicialmente, partiu de alguns princípios de planejamento de textos e da relação de textos e imagens advindos das pesquisas empíricas 
de Mayer e colaboradores. O primeiro princípio de que fizemos uso foi o chamado princípio de sinalização. Algumas pesquisas (por exemplo: HARP; MAYER, 1998; MAUTONE; MAYER, 2001) mostram que a aprendizagem é mais eficiente quando existem sinais ou pistas que indicam, no texto, o que deve ser analisado na imagem. Direcionar a atenção do aluno leva-o a focar os elementos importantes para os objetivos da lição e facilita a seleção e organização na memória operacional (CLARCK; LYONS, 2004, p. 71; MAYER, 2005). A ausência de tais sinalizações pode tornar a busca por informação demorada, excedendo os limites da memória operacional. Estes sinais podem ser diversos, tais como números no texto e na imagem, indicando a etapa do processo. Também se pode usar cor, de tal forma que a cor da palavra no texto corresponda a algum elemento da imagem, na mesma cor.

A imagem do Ciclo do Nitrogênio presente em Amabis e Martho não satisfaz ao critério de sinalização. Alguns termos encontram-se em negrito no texto, mas os mesmos não estão destacados na imagem. Outro problema de sinalização encontrado foi que, apesar de a imagem do Ciclo apresentar os processos de fixação, nitrificação e desnitrificação, a parte do texto onde se encontra a referencia "Fig. 14.13", referente ao ciclo, descreve apenas a desnitrificação.

A coleção de Linhares e Gewandsznajder também não satisfaz ao critério de sinalização. Alguns elementos do Ciclo do Nitrogênio estão destacados no texto, mas não na imagem. As referências à imagem não se encontram destacadas.

As palavras decomposição, fixação do nitrogênio, nitrosação, nitratação e desnitrificação aparecem em negrito na imagem do Ciclo do Nitrogênio presente na coleção de Paulino, mas os mesmos conceitos não estão destacados no texto. Apesar de não estar destacada, ao final da explicação do ciclo foi colocada a sinalização " $\mathrm{Na}$ figura 15.4 você tem um resumo esquemático do ciclo do nitrogênio na natureza:", amenizando o problema de sinalização.

As etapas do Ciclo do Nitrogênio encontram-se numeradas tanto na imagem quanto no texto da coleção de César e Sezar, mas esses números não estão destacados. Alguns conceitos do ciclo estão destacados no texto, mas não na imagem.

O segundo princípio de que fizemos uso foi o de contiguidade. Várias pesquisas (p. ex., MAYER, 1989; SWELLER et al., 1990; CHANDLER; SWELLER, 1991 e MORENO; MAYER, 1999) indicam que uma forma de reduzir o processamento supérfluo é colocar o texto verbal próximo à imagem que ele descreve. Quando texto e imagem estão integrados, o leitor não precisa usar seus recursos cognitivos para uma busca visual na página ou em páginas distantes, facilitando o armazenamento de informações na memória operacional (MAYER, 2001, p. 81).

Quanto ao princípio de contiguidade, as imagens presentes nas coleções de Amabis e Martho, Linhares e Gewandsznajder e Paulino encontram-se distantes do texto explicativo sobre o Ciclo do Nitrogênio, até mesmo em pági- 
nas diferentes. A imagem apresenta contiguidade com o texto apenas na coleção escrita por César e Sezar.

Um terceiro princípio explorado por nós foi o de contextualização. Chamamos de contextualização a indicação de Mayer et al. (2002) segundo a qual, o ideal é apresentar as partes principais do sistema e somente depois introduzir os detalhes. Com base nisto, uma imagem que descreve o Ciclo do Nitrogênio deveria vir antecedida de uma imagem que resumisse as principais etapas do ciclo. Tal estratégia favoreceria a formação de um esquema geral do Ciclo do Nitrogênio na memória de longa duração, permitindo ao aluno, posteriormente, dar significado para os detalhes deste processo.

Quanto ao critério de contextualização, Amabis e Martho introduzem uma figura mostrando as etapas de formação de nódulos de rizóbios (bactérias fixadoras de nitrogênio) em raízes de leguminosas, uma foto e uma fotomicrografia desses nódulos, antes da imagem do ciclo. Entretanto, estas imagens não auxiliam na contextualização do Ciclo do Nitrogênio, pois não fornecem informações que ajudem na sua compreensão. Apenas uma imagem, com todos os detalhes do ciclo, foi apresentada ao final das explicações, concluindo-se que, neste caso, não é satisfeito o critério de contextualização.

Linhares e Gewandsznajder fazem o processo inverso do considerado como contextualização. Apresentam, primeiramente, uma imagem detalhada do Ciclo do Nitrogênio e, por último, após as explicações, outra imagem, representando o Ciclo de forma simplificada. A imagem presente em Paulino também não satisfaz ao critério de contextualização, pois apresenta apenas uma imagem do Ciclo do Nitrogênio, com todos os detalhes.

Algumas etapas do Ciclo do Nitrogênio foram contextualizadas em César e Sezar. Essa contextualização foi feita por quatro esquemas que segmentam o Ciclo nos processos de amonização, nitrosação, nitratação e nitrificação. O Ciclo completo foi colocado ao final das explicações sem, no entanto, que tivessem sido previamente apresentados outros processos que também fazem parte do Ciclo. Duas outras imagens, que não acrescentam informações relevantes para o entendimento do Ciclo, foram colocadas. Tais imagens podem ser consideradas supérfluas.

Além dos princípios citados acima, nossa análise mostrou outras três formas problemáticas de modo de exibição da informação no livro didático de Biologia. Assim, como dissemos, propomos três novos princípios de análise da mensagem instrucional que faz uso de texto verbal e imagem. Ao primeiro princípio chamamos continuidade verbal. Neste caso, a informação necessária para se entender um conceito deve estar próxima de onde o conceito ocorre. Segundo o modelo cognitivo de que fazemos uso, se o aluno não fixou este conceito na memória de longa duração, a compreensão do texto estará comprometida. $\mathrm{O}$ ideal seria, então, que as informações necessárias estivessem localizadas no próprio texto, seja por meio de notas ou de caixas de texto.

Para analisarmos o princípio de continuidade verbal nas informações sobre o Ciclo do Nitrogênio, fizemos um levantamento dos conceitos que não 
apresentavam todas as informações necessárias à sua compreensão. Percebe-se, nos livros de autoria de Amabis e Martho, Linhares e Gewandsznajder, e Paulino, uma descontinuidade verbal em relação à ênfase dada aos conceitos trazidos da Química, tais como nomes de reações e de reagentes. Entre essas reações, estão a fotossíntese, a quimiossíntese, a oxidação (respiração aeróbica) e a respiração anaeróbica. Esses conceitos confundem-se aos de fixação, amonificação, nitrificação, nitrosação, nitratação, desnitrificação e decomposição, aumentando ainda mais a complexidade e diminuindo as chances de compreensão. Nenhum dos três livros apresenta explicações suficientes para a compreensão desses conceitos, sendo necessária a intervenção do professor. Além desses, outros conceitos próprios da Biologia, sem informações suficientes para a sua compreensão, também foram encontrados (cianobactérias, níveis tróficos, cadeia alimentar, aminoácidos, proteínas, ácidos nucleicos, eucariontes). Para o professor que escolhe apresentar o Ciclo do Nitrogênio a partir da compreensão detalhada de todas as suas etapas, é necessário estar atento a essa nomenclatura.

Ao contrário do que foi exposto, o Ciclo do Nitrogênio foi apresentado por César e Sezar de uma forma mais simplificada, incluindo, mas não dando ênfase às especificidades das reações químicas e dos reagentes. Essa maneira de apresentar o Ciclo do Nitrogênio facilita o trabalho do professor que opta por apresentá-lo de uma maneira mais geral.

O segundo princípio proposto por nós é a complementaridade texto/imagem, ou seja, a informação do texto escrito deveria aparecer na imagem. Quando isto não ocorre, o aluno pode perder tempo ao procurar uma informação que não está lá. Também pode ocorrer da informação ser desconsiderada, caso o aluno decida estudar a partir do esquema ilustrativo.

Finalmente, o terceiro princípio que propomos é denominado por nós de complementaridade imagem/texto. Ou seja, o que é dito no texto escrito e aparece na imagem, deveria ser nomeado na imagem. No entanto, isto, algumas vezes, não ocorre. Existem elementos na imagem sem qualquer indicação sobre do que se trata. Neste caso, a análise da imagem toma muito tempo do aluno, pois seus recursos de memória operacional são utilizados para se entender a relação daqueles detalhes com o texto ou sobre os seus papéis na imagem.

Considerando-se os dois últimos critérios descritos acima, percebe-se complementaridade, tanto texto/imagem quanto imagem/texto, entre as informações escritas sobre o Ciclo do Nitrogênio e a imagem desse Ciclo no livro de Amabis e Martho e de César e Sezar.

$\mathrm{Na}$ imagem do Ciclo apresentado por Linhares e Gewandsznajder, encontram-se elementos que levam tanto a uma não complementaridade texto/imagem, quanto a uma não complementaridade imagem/texto. A não complementaridade texto/imagem pode ser notada pela ausência, na imagem, de informações presentes no texto, tais como a formação de aminoácidos e a fixação do N2 pela ação de relâmpagos. Nota-se a não complementaridade imagem/texto quando não se encontram nomeadas na imagem as fórmulas quími- 
cas dos compostos, os nomes das bactérias fixadoras, as bactérias fixadoras presentes nas raízes das leguminosas, as próprias leguminosas, os cadáveres e excretas utilizados por decompositores, o processo de nitrificação.

A não complementaridade texto/imagem presente nas informações sobre o Ciclo do Nitrogênio dadas por Paulino acontece devido à não inclusão de informações sobre a fixação do N2 pelas bactérias do gênero Rhizobium que formam nódulos nas raízes das leguminosas. A não complementaridade imagem/texto se dá pela não discriminação ou supressão, na imagem, dos tipos de bactérias responsáveis por cada etapa do Ciclo do Nitrogênio. O quadro 1 resume os resultados de nossa análise.

Quadro 1: Resumo da análise das quatro coleções

\begin{tabular}{|c|c|c|c|c|}
\hline Principio & Amabis e Wartho & $\begin{array}{c}\text { Lirkares e } \\
\text { Ge wandsenajder }\end{array}$ & Faulino & Cesar e Sezar \\
\hline Siralizar:ăo & $\begin{array}{l}\text { - Elementos } \\
\text { destacados no texto, } \\
\text { mas năo na imagem. } \\
\text { - Parte do texto onde } \\
\text { se encontra a } \\
\text { referén ria da figura } \\
\text { descreve apenas a } \\
\text { desnitrificaçäo. }\end{array}$ & $\begin{array}{l}\text { - Elementos } \\
\text { destacados no texto, } \\
\text { mas năo na iragem. } \\
\text { - Referênc ias à } \\
\text { imagem năo } \\
\text { destacadas. }\end{array}$ & $\begin{array}{l}\text { - Elemeritos } \\
\text { de stacados na } \\
\text { imagera mas } \\
\text { não no te xto. } \\
\text { - Referencia a } \\
\text { figura feita de } \\
\text { ruarueira } \\
\text { adequada. }\end{array}$ & $\begin{array}{l}\text { - Elernentos } \\
\text { destacados no texto, } \\
\text { mas năo na imagern. } \\
\text { - Etajas numbradas } \\
\text { tanto na imagem } \\
\text { quanto no texto. }\end{array}$ \\
\hline Contigiidade & \multicolumn{3}{|c|}{$\begin{array}{l}\text { Imagens distantes do texto explica tro, até mesmo em páginas } \\
\text { difê re rtes. }\end{array}$} & $\begin{array}{l}\text { Irrageru apresenta } \\
\text { contigiidade como } \\
\text { texto. }\end{array}$ \\
\hline Contextualizaça ão & $\begin{array}{l}\text { Apresenta outras } \\
\text { imagens, mas que } \\
\text { năo auxiliarn ra } \\
\text { contextualiząáo. }\end{array}$ & 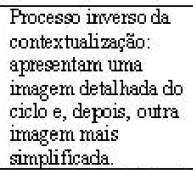 & $\begin{array}{l}\text { Apresenta } \\
\text { apenas uria } \\
\text { imagern do } \\
\text { Ciclo do } \\
\text { Nitrogênio, com } \\
\text { todos os } \\
\text { de talhes. }\end{array}$ & $\begin{array}{l}\text { Quatro etapas do } \\
\text { Ciclo do litrogénio } \\
\text { forart } \\
\text { contex tualizadas por } \\
\text { meio de esquemas. }\end{array}$ \\
\hline Continuidade werbal & \multicolumn{3}{|c|}{$\begin{array}{l}\text { Descontinuidade verbal em re lação a ênfase dada aos conceitos } \\
\text { tracidos da Qhuirica, como nomes de reaçoses e de reagentes, e da } \\
\text { presença, serm explicaçán, de algums termos da Biologia. }\end{array}$} & $\begin{array}{l}\text { We rium elemento } \\
\text { que indique, de } \\
\text { forma significativa, } \\
\text { urna } \\
\text { descontinuidade } \\
\text { verbal. }\end{array}$ \\
\hline $\begin{array}{l}\text { Compleme ndaridade } \\
\text { textolirnage iri }\end{array}$ & $\begin{array}{l}\text { Werhum elernento } \\
\text { que indique, de } \\
\text { forma sigrificativa, } \\
\text { urna năo } \\
\text { complementaridade } \\
\text { textolimagem. }\end{array}$ & $\begin{array}{l}\text { Alusencia, na irnagem, } \\
\text { de irfornaç óes } \\
\text { pe sertes no texto. }\end{array}$ & $\begin{array}{l}\text { Ausência, na } \\
\text { imageru, de } \\
\text { informaçós } \\
\text { presentes no } \\
\text { texto. }\end{array}$ & $\begin{array}{l}\text { Wertum elemento } \\
\text { que irdique, de } \\
\text { forma significativa, } \\
\text { urna não } \\
\text { complementaridade } \\
\text { textolimagem. }\end{array}$ \\
\hline $\begin{array}{l}\text { Corriplerue ruaridade } \\
\text { imagemitexto }\end{array}$ & $\begin{array}{l}\text { Nerhuru elernento } \\
\text { que indique, de } \\
\text { forma significatina, } \\
\text { urna näo } \\
\text { complementaridade } \\
\text { imagenitexto. }\end{array}$ & $\begin{array}{l}\text { Wá forard nomeados } \\
\text { na iriagem } \\
\text { deteminados } \\
\text { elementos prese ntes } \\
\text { no texto. }\end{array}$ & $\begin{array}{l}\text { Nono forarn } \\
\text { nomieados na } \\
\text { imageru. } \\
\text { de terrimados } \\
\text { e lernentos } \\
\text { presentes no } \\
\text { texto. }\end{array}$ & $\begin{array}{l}\text { We ritum elemento } \\
\text { que indigue, de } \\
\text { foma significativa, } \\
\text { uma não } \\
\text { complementaridade } \\
\text { irrage roi texto. }\end{array}$ \\
\hline
\end{tabular}

Como se pode ver, os seis princípios para apresentação de uma mensagem instrucional que faz uso de texto verbal e imagens, de modo geral, não foram satisfeitos nos livros analisados. A violação destes princípios implica a imposição de uma carga cognitiva supérflua sobre os recursos cognitivos do aluno. Portanto, quanto ao tema analisado, em todos os livros analisados encontramos um planejamento instrucional inapropriado. 


\section{Considerações Finais}

Segundo o referencial teórico de que fizemos uso, nosso estudo apontou problemas na composição e forma de apresentação das imagens no livro didático de Biologia. Se considerarmos que tanto o espaço do livro didático, quanto o tempo e as capacidades cognitivas do aluno são limitados, os planejadores e construtores de livros didáticos devem ficar atentos a estes problemas. $\mathrm{O}$ estudo do tema Ciclo do Nitrogênio nas quatro coleções indica a necessidade de que o planejamento e a construção de imagens para o livro didático de Biologia sejam orientados por preceitos e critérios que visem tornar o uso dos recursos pictóricos mais eficientes.

Esperamos que os resultados desta pesquisa possam também orientar a ação do professor em sala de aula. Os professores podem estabelecer estratégias de leitura com seus alunos, com o objetivo de facilitar o uso do livro didático, distinguindo aspectos meramente ilustrativos e separando e apontando as informações essenciais. Pesquisas que levem à criação e difusão destas estratégias, no momento, seriam fundamentais para o uso apropriado do livro didático de Biologia.

Como assinalado, o uso de imagem aliadas ao texto verbal é uma característica das Ciências Naturais como um todo e não só da Biologia. Portanto, análises dos livros didáticos de Química e Física, bem como dos livros didáticos de Ciências, em muito ampliariam nosso conhecimento sobre as formas de planejamento de tais livros no Brasil.

A estratégia teórico-metodológica aqui apresentada aponta para a possibilidade de construção de uma ferramenta de avaliação do livro didático de Biologia, quanto a um layout que se interessa pelos recursos cognitivos do aluno. A eficácia de tal ferramenta seria maior se outros aspectos da cognição humana fossem considerados. Neste caso, não só o modelo do sistema mnemônico e a teoria da carga cognitiva são relevantes, mas também os resultados das pesquisas neurocientíficas e cognitivas sobre percepção e atenção.

Ainda, nossa pesquisa restringiu-se a uma análise qualitativa sobre o modo de apresentação dos livros analisados. No entanto, uma abordagem quantitativa que abrangesse o domínio de categorizar diferenças entre os livros poderia contribuir para a construção da ferramenta de avaliação mencionada acima.

Finalmente, o que aqui se enunciou, mesmo que seguindo os rigores metodológicos descritos, em muito se enriqueceria com replicações do trabalho. Tais replicações, que focassem outros temas tratados no livro didático de Biologia, poderiam dar maior consistência aos nossos achados, bem como levar a novas propostas de análise com base nas capacidades cognitivas do aluno. Novamente, estudos sobre percepção e atenção em muito podem contribuir. 


\section{REFERÊNCIAS BIBLIOGRÁFICAS}

AMABIS, J. M. E. \& MARTHO, G. R. Biologia das Populações. São Paulo, Editora Moderna, 2004. BADDELEY, A. Working memory. Science, 255: 556-559, 1992.

BADDELEY, A. A Short-term and working memory. In: Tulving, E. \& Craik, F. I. M. (Eds.). The Oxford handbook of memory. Oxford: Oxford University Press, 2000, pp. 77-92.

BRUZZO, C. Biologia: educação e imagens. Educação e Sociedade, 25 (89): 1359-1378, 2004.

CAMPOS, A. F. Ciclo do nitrogênio: abordagem em livros didáticos de Ciências do Ensino Fundamental. Investigações em Ensino de Ciências, 13 (1): 35-44, 2008.

CÉSAR, S. J. \& SEZAR, S. Biologia. Volume 3, São Paulo, Editora Saraiva, 2005.

KNORR-CETINA, K. \& AMANN, K. Image Dissection in Natural Scientific Inquiry. Science, Technology and Human Values, 15: 259-283, 1990.

LEMKE, J. Multiplying meaning: Visual and verbal semiotics in scientific text. In: MARTIN, J. R. and VEEL, R. Reading Science. London: Routledge, 1998.

LINHARES, S. E. \& GEWANDSZNAJDER, F. Biologia hoje, Volume 3. São Paulo, Editora Ática, 2003.

MARTINS, I.; GOUVÊA, G. \& PICCININI, C. L. Aprendendo com imagens. Ciência e Cultura, 57 (4): 38-40, 2005.

MAYER, R. E. Multimedia learning. Cambridge, Cambridge University Press, 2001.

MAYER, R. \& ANDERSON, R. B. Animations need narrations: an experimental test of dual-coding hypothesis. Journal of Educational Psychology, 83: 484-490, 1991.

MAYER, R. E. \& ANDERSON, R. B. The instructive animation: helping students build connections between words and pictures in multimedia learning. Journal of Educational Psychology, 84: 444452, 1992.

MAYER, R. E. \& GALLING, J. K. When is an illustration worth ten thousand words? Journal of Educational Psychology, 82: 715-726, 1990.

PAULINO, W. R. Biologia Atual, Volume 3. São Paulo, Editora Ática, 2002.

PICCININI, C. \& MARTINS, I. Comunicação multimodal na sala de aula de Ciências: construindo sentidos com palavras e gestos. Ensaio: pesquisa em ensino de Ciências, 6 (1): 1-14, 2004.

POZZER-ARDENGHI, L. \& ROTH, W. M. Photographs in lectures: gestures as meaning-making resources. Linguistics and Education, 15: 275-293, 2005. 
